NOT FOR QUOTATION

WITHOUT THE PERMISSION

OF THE AUTHOR

\title{
HOW CHANGE IN AGE-SPECIFIC MORTALTTY AFFECTS LIFE EXPECTANCY
}

J.W. Vaupel

March 1985

WP- $85-17$

Working Papers are interim reports on work of the International Institute for Applied Systems Analysis and have received only limited review. Views or opinions expressed herein do not necessarily represent those of the Institute or of its National Member Organizations.

INTERNATIONAL INSTITUTE FOR APPLIED SYSTEMS ANALYSIS 2361 Laxenburg, Austria 


\section{Summary}

At current mortality rates, life expectancy is most responsive to change in mortality rates at older ages. Mathematical formulas that describe the linkage between change in age-specific mortality rates and change in life expectancy reveal why. These formulas also shed light on how past progress against mortality has been translated into increases in life expectancy-and on the impact that future progress is likely to have. Furthermore, the mathematics can be adapted to study the effect of mortality change in heterogeneous populations in which those who die at some age would, if saved, have a different life expectancy than those who live. 


\section{Acknowledgments}

I thank Nathan Keyfitz, Kenneth Manton, and Anatoli Yashin for their insights and suggestions and Carolyn Fuhrmann and Susanne Stock for their help in preparing the manuseript. 


\title{
HOW CHANGE IN AGE-SPECIFIC MORTALITY AFFECTS LIFE EXPECTANCY
}

\author{
J.W. Vaupel
}

\section{INTRODUCTION}

Suppose the goal is to increase the life expectancy of a population. Or, equivalently, assume the objective is to save as many life years as possible. If 100 deaths could be averted in any decade of life--0 to 10 , say, or 42 to 52-which decade would be best? The answer is simple--the first decade of life, because children lose the most years of life expectancy. Suppose, however, deaths could be reduced by one percent in any decade of life. Which decade would then be best?

It may seem reasonable, at first thought, to guess 0 to 10 , or 17 to 27 , or some other young decade. Using the life table for Swedish males for 1982, however, the correct answer is 67 to 77 . And using the life table for Swedish females for 1982 the answer is 74 to 84 .

The Swedish life table indicates that out of a synthetic cohort of 100,000 women, 13 girls would die between their tenth and eleventh birthdays. Life expectancy at age 10.5 is about 69.5 years. The product approximates the number of years of life expectancy lost-just over 900 life years. At age 80, more than 3600 women die, losing 7.7 years of life expectancy. The product gives 28,000 life years. More than thirty times as many years of life expectancy are lost at age 80 than at age 10.

Large numbers of life years are lost in infancy. In the Swedish female life table, 653 infants under age one die, losing about 79.2 years of life expectancy each, or about 52 thousand years all together. But only 189 additional girls die between ages one and 10; the total loss of life expectancy between birth and age 10 is about 66 thousand years. Compared with these 842 deaths, nearly 32,000 women die in the decade between age 74 and 84 . They lose about 8.3 years of life expectancy on average, or about 260 thousand years all together. Thus, four times as many years of life expectancy are lost in the decade between ages 74 and 84 as are lost in the first ten years of life. 


\section{HOT REDUCTIONS IN MORTALITY INCREASE LIFE EXXPETANCY}

Let $\mu(\alpha, t)$ be the force of mortality and $p(a, t)$ be the period survivorship at age $a$ and time $t ; \mu$ and $p$ are interrelated by the familiar formulas:

$$
\mu(a, t)=-\frac{d p(a+x, t+x) / d x}{p(a, t)} \text { at } x=0
$$

and

$$
p(a, t)=e^{-\int_{0}^{a} \mu(x, t) d x}
$$

Let $\stackrel{e}{e}(a, t)$ represent period life expectancy, given by the well-known formula:

$$
\dot{e}(a, t)=\int_{a}^{\omega} p(x, t) d x / p(a)
$$

where $\omega$ is an age beyond which no one survives. Note that life expectancy at birth is given by:

$$
\dot{e}_{0}(t)=\ddot{e}(0, t)=\int_{0}^{\omega} p(x, t) d x
$$

How does change in the trajectory of $\mu$ affect $\stackrel{0}{e}$ ? Demographers have taken two basic approaches in answering this question. The first, exemplified by Pollard [1] and in a United Nations study [2], focuses on how the difference between two alternative trajectories-- $\mu^{1}(\alpha)$ and $\mu^{2}(a)$, say--translates into the difference between the resulting life expectancies, $e^{1}$ and $e^{2}$. The second approach, pioneered by Keyfitz [3] and extended here, focuses on how the rate or intensity of progress in $\mu$, given by

$$
\rho(a, t)=-\frac{\partial \mu(a, t) / \partial t}{\mu(a, t)}
$$

translates into the rate of progress in life expectancy, given by

$$
\pi(t)=\frac{\stackrel{\partial}{e}(0, t) / \partial t_{0}^{0}(0, t)}{e} .
$$


It follows from (4) that

$$
\pi(t)=\frac{\int_{0}^{\omega} p(a, t) \cdot \int_{0}^{a} \mu(x, t) p(x, t) d x d a}{\int_{0}^{\omega} p(a, t) d a} .
$$

As shown by Keyfitz [3], if equal progress is being made against mortality at all ages at time $t$, i.e.,

$$
\rho(a, t)=\rho(t), \quad \text { all } a .
$$

then

$$
\pi(t)=\rho(t) H(t)
$$

where

$$
H(t)=\frac{\int_{0}^{\omega} p(a, t) \cdot \int_{0}^{a} \mu(x, t) d x d a}{\int_{0}^{\omega} p(a, t) d a} .
$$

Because

$$
\int_{0}^{a} \mu(x, t) d x=-\ln p(a)
$$

$H(t)$ can also be calculated by

$$
H(t)=\frac{-\int_{0}^{\omega} p(a, t) \ln p(a, t) d a}{\int_{0}^{\omega} p(a, t) d a} .
$$

As discussed by Demetrius [4,5] and Keyfitz [3], $H$, which is a variant of the measure known as entropy or information in other contexts, can be interpreted as a measure of the homogeneity of a population over age with respect to mortality: if $H$ equals zero, then everyone dies at the same age; if $H$ equals one. then the force of mortality is equal at all ages. As indicated by (9), $H$ gives the percentage change in life expectancy produced by a one percent reduction in the force of mortality at all ages: if $H$ is 0.2 , say, then a uniform one percent de- 
crease in $\mu$ would increase $\stackrel{0}{e}_{0}$ by 0.2 percent. As Keyfitz [6] further explains, "male mortality is clearly higher than female in most rich countries, usually by 50 percent or more at typical ages. But $\stackrel{\circ}{e}_{0}$ is only about 10 percent greater for females .... The parameter $H \ldots$ is intended to carry one from the 50 percent to the 10 percent".

An alternative expression for $H$ is revealing. It follows from (7) that

$$
\begin{aligned}
\pi(t) & =\frac{\int_{0}^{\omega} \int_{0}^{a} p(a, t) \mu(x, t) \rho(x, t) d x d a}{\int_{0}^{\omega} p(a, t) d a} \\
& =\frac{\int_{0}^{\omega} \int_{x}^{\omega} p(a, t) \mu(x, t) \rho(x, t) d a d x}{\int_{0}^{\omega} p(a, t) d a} \\
& =\frac{\int_{0}^{\omega} \mu(x, t) \rho(x, t) \cdot \int_{x}^{\omega} p(a, t) d a d x}{\int_{0}^{\omega} p(a, t) d a} .
\end{aligned}
$$

Substituting (3) and (4) yields

$$
\pi(t)=\frac{\int_{0}^{\omega} \mu(x, t) p(x, t) \stackrel{0}{e}(x, t) \rho(x, t) d x}{\dot{\varepsilon}_{0}(t)} .
$$

Let

$$
\eta(x, t)=\mu(x, t) p(x, t) \stackrel{0}{e}(x, t) / \stackrel{0}{e_{0}}(t)
$$

so that $\eta$ represents the total number of years of life expectancy lost by those who die at age $x$, divided by life expectancy at birth. Then

$$
\pi(t)=\int_{0}^{\omega} \eta(x, t) \rho(x, t) d x
$$


Three special cases are of interest:

i) If progress against mortality is uniform at all ages,

$$
\rho(x, t)=\rho(t), \text { all } x
$$

then

$$
\pi(t)=\rho(t) \int_{0}^{\omega} \eta(x, t) d x
$$

By comparing (9) and (18), it is clear that $H$ (which is, fittingly, the symbol for capital $\eta$ ) is given by

$$
H(t)=\int_{0}^{\omega} \eta(x, t) d x
$$

Substituting (15) yields

$$
H(t)=\frac{\int_{0}^{\infty} \mu(x, t) p(x, t) e^{0}(x, t) d x}{e_{0}(t)} .
$$

Because the product of $\mu$ and $p$ gives the density of deaths at age $x$, this formula helps reveal why $H$ is a measure of the homogeneity of a population with regard to age of death (or lifespan). Furthermore, this formula facilitates understanding of why $H$ is a measure of the percentage increase in life expectancy generated by a one percent decrease in mortality rates. If a death is averted at age $x$, then $\stackrel{0}{e}(x)$ years of life expectancy are gained. The numerator of (20) measures the total effect of reducing deaths at all ages; the denominator converts the absolute effect into a relative effect. As suggested to me by my colleague Anatoli I. Yashin, this implies that $H(t)$ gives the proportional increase in life expectancy at birth if everyone's first death were averted. The assumption is that each individual at the hour of death is saved and given the life expectancy of individuals surviving at that age. Thus, if $H(t)$ is 0.15 , staying the hand of death once would increase life expectancy by 15 percent. Compared with (20), the expressions for $H$ given in (10) and (12) seem less intuitive.

ii) If progress against mortality only occurs between ages $\alpha$ and $\beta$ and if the rate of progress is uniform between these ages, then

$$
\pi(t)=\rho(t) \int_{\alpha}^{\beta} \eta(x, t) d x
$$


This formula was used to answer the question posed at the start of this paper.

iii) Finally, if progress against mortality only occurs at a single instantaneous age $a$,

$$
\rho(x, t)=\delta(x-a) \rho(t)
$$

where $\delta$ is a Dirac function, then

$$
\pi(t)=\rho(a, t) \eta(a, t)
$$

Thus, $\eta(\alpha)$ is a measure of the potential for increasing life expectancy by reducing the force of mortality at age $a$. Because $\eta(a)$ is proportional to $\mu(a) p(a)$ and $\stackrel{e}{e}(\boldsymbol{a})$, this potential depends both on the density of deaths at age $a$ and on the number of years of life expectancy lost by those dying at age $a$. The implicit assumption is that the population is homogeneous at any specific age: those who die would, if they could be saved, have the same life expectancy as those who live. This assumption will be relaxed later in this paper.

\section{THE POTENTIAL FOR SAVING LITE YFARS}

Table 1 presents values of $\int_{x}^{x+5} \eta(a) d a$ for Swedish males and females in 1982*. After infancy, the maximum value of $\eta$ for the men occurs at age 72.5 ; for the women, it occurs at age 80.0. A one percent reduction in the force of mortality between ages 75 and 80 would increase male life expectancy by .036 percent and female life expectancy .031 percent. A one percent reduction in the force of mortality at all ages would increase male life expectancy by about .15 percent and female life expectancy by about .13 percent.

\footnotetext{
-A number of different life tables, from different sources, were used to make the calculation in this paper. The life tables for Sweden from 1780 to 1950 are from [7]; Swedish life tables after 1950, except for 1970 and 1982, are from the annual Swedish Statistical Yearbook. These various life tables are based on five years of data centered on the year given: the 1910 table, for example, is based on data from 1908 through 1812. The Swedish life tables for 1970 and 1882 were supplied by Professor Ingvar Holmberg of the University of Gothenberg: these tables pertain to a single year of time. The U.S. life table for 1978 is based on the advanced report of final mortality statistics in the Monthly Vital Statistics Report, September 1982; the figures were adjusted by the correction factors given in that Report so that they are consistent with population estimates based on the $18 B 0$ census. The U.S. life table for 1970 is the decennial table based on data from 1969 through 1971, as published in "United States Life Tables: 1969-71" (National Center for Health Statistics, May 1975). The U.S. life table for 1800 is from [8]. The U.S. life tables for 1980 and 2000 are from "Life Tables for the United States: 1800-2050", Actuarial Study No. 87, U.S. Dept. of Health and Human Services, September 1982. All the remaining life tables pertaining to years between 1975 and 1879 are from the United Nations DemoBraphic Yearbook 1880. All other life tables are from [7].
} 
Table 1. Values of $\int_{x}^{x+5} \eta(\alpha) d a$ for Swedish males and females in 1982.

\begin{tabular}{lcc}
\hline Age Period & Males & Females \\
\hline $0-5$ & .00853 & .00763 \\
$5-10$ & .00085 & .00068 \\
$10-15$ & .00060 & .00060 \\
$15-20$ & .00226 & .00079 \\
$20-25$ & .00289 & .00120 \\
$25-30$ & .00344 & .00140 \\
$30-35$ & .00341 & .00172 \\
$35-40$ & .00434 & .00243 \\
$40-45$ & .00530 & .00313 \\
$45-50$ & .00736 & .00447 \\
$50-55$ & .00942 & .00591 \\
$55-60$ & .01258 & .00779 \\
$60-65$ & .01555 & .00936 \\
$65-70$ & .01788 & .01202 \\
$70-75$ & .01869 & .01464 \\
$75-80$ & .01719 & .01679 \\
$80-85$ & .01282 & .01650 \\
$85-90$ & .00675 & .01201 \\
$90-95$ & .00231 & .00545 \\
$95-100$ & .00055 & .00142 \\
$H$ (i.e., total for & .15270 & .12622 \\
all ages) & & \\
\hline
\end{tabular}

In which round five-year period (e.g., 25-30 or 60-65), not counting early childhood from 0 to 5 , is the potential for saving life years greatest? Table 2 presents the answer for an assortment of countries at different times with varying life expectancies. The rough rule of thumb is that the optimal five year period is near the life expectancy of the population: the rule holds particularly well for populations with life expectancies of 65 years or more.

A simple model and some elementary calculus sheds some light on this finding. If the force of mortality follows a Gompertz curve,

$$
\mu(a)=\alpha e^{\beta a} .
$$

then it follows from (15), (3) and (2) that

$$
\eta(a)=\alpha e^{\beta a} \int_{a}^{\omega} e^{-\frac{a}{\beta}\left(\beta^{\beta z}-1\right)} d x / \ddot{e}_{0} .
$$


Setting the derivative of $\eta(a)$ with respect to a equal to zero yields the result that the maximum value of $\eta(a)$ occurs at the value of $a$ such that

$$
\stackrel{e}{e}(\alpha)=1 / \beta .
$$

For a Gompertz curve of mortality, this value of a turns out to be roughly equal to life expectancy at birth.

Table 2. The five-year period following infancy for which the potential for saving lives years is greatest, for various male and female populations with different life expectancies, from different countries, at different periods.

\begin{tabular}{|c|c|c|c|c|}
\hline & & & $\begin{array}{c}\text { 5-year period } \\
\text { following infancy } \\
\text { for which } \int_{a}^{a+5} \eta(x) d x\end{array}$ & \\
\hline Country & Period & Sex & is greatest & $e_{0}$ \\
\hline Italy & 1881 & $\mathrm{M}$ & $20-25$ & 33 \\
\hline Sweden & 1780 & M & & 36 \\
\hline USA & 1900 & M & & 46 \\
\hline Taiwan & 1920 & $\mathrm{M}$ & $25-30$ & 27 \\
\hline Taiwan & 1920 & $\mathrm{~F}$ & & 29 \\
\hline Chile & 1909 & M & & 29 \\
\hline Chile & 1909 & $\mathrm{~F}$ & & 33 \\
\hline Italy & 1881 & $\mathrm{~F}$ & & 34 \\
\hline England and Wales & 1861 & $\mathrm{~F}$ & & 43 \\
\hline USA & 1900 & $\mathrm{~F}$ & & 48 \\
\hline Sweden & 1780 & $\mathrm{~F}$ & $30-35$ & 39 \\
\hline England and Wales & 1861 & $\mathrm{M}$ & & 40 \\
\hline Japan & 1899 & $\mathrm{~F}$ & $35-40$ & 44 \\
\hline Japan & 1899 & $\mathrm{M}$ & $55-60$ & 42 \\
\hline Czechoslovakia & 1934 & $\mathrm{M}$ & & 52 \\
\hline Australia & 1911 & $\mathrm{M}$ & $60-65$ & 58 \\
\hline Costa Rica & 1960 & $\mathrm{M}$ & & 63 \\
\hline Mexico & 1975 & M & & 63 \\
\hline Czechoslovakia & 1934 & $\mathrm{~F}$ & $65-70$ & 56 \\
\hline Australia & 1911 & $\mathrm{~F}$ & & 61 \\
\hline Chile & $1979-80$ & $M$ & & 61 \\
\hline Costa Rica & 1960 & $\mathrm{~F}$ & & 65 \\
\hline Poland & 1960 & M & & 65 \\
\hline Australia & 1964 & M & & 67 \\
\hline Mexico & 1975 & $\mathrm{~F}$ & & 67 \\
\hline USA & 1970 & M & & 67 \\
\hline Japan & 1964 & M & & 68 \\
\hline Canada & 1965 & M & & 69 \\
\hline England and Wales & $1976-78$ & $\mathrm{M}$ & & 70 \\
\hline USA & 1980 & $\mathrm{M}$ & & 70 \\
\hline USA & 2000 & M & & 73 \\
\hline
\end{tabular}


Table 2 (continued)

\begin{tabular}{|c|c|c|c|c|}
\hline \multirow[b]{2}{*}{ Country } & \multirow[b]{2}{*}{ Period } & \multirow[b]{2}{*}{ Sex } & \multirow{2}{*}{ 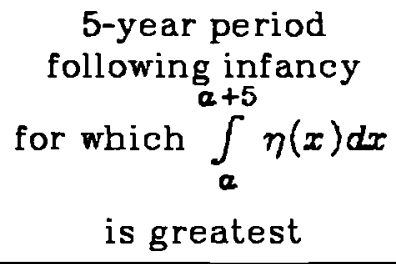 } & \multirow[b]{2}{*}{$\dot{\theta}_{0}$} \\
\hline & & & & \\
\hline Chile & 1979-B0 & $\mathrm{F}$ & $70-75$ & 68 \\
\hline Poland & 1960 & $\mathrm{~F}$ & & 71 \\
\hline Sweden & 1978 & M & & 72 \\
\hline Japan & 1964 & $F$ & & 73 \\
\hline Japan & 1978 & $\mathrm{M}$ & & 73 \\
\hline Sweden & 1982 & $\mathrm{M}$ & & 73 \\
\hline Australia & 1964 & $F$ & & 74 \\
\hline Iceland & $1977-78$ & $\mathrm{M}$ & & 74 \\
\hline Canada & 1965 & $\mathrm{~F}$ & & 75 \\
\hline USA & 1970 & $\mathrm{~F}$ & $75-80$ & 75 \\
\hline England and Wales & $1976-78$ & $\mathrm{~F}$ & & 76 \\
\hline USA & 1980 & $F$ & & 78 \\
\hline Japan & 1978 & $\mathrm{~F}$ & & 78 \\
\hline Sweden & 1978 & $\mathrm{~F}$ & & 79 \\
\hline Sweden & 1982 & $\mathrm{~F}$ & & 79 \\
\hline Iceland & $1977-78$ & $F$ & $80-85$ & 79 \\
\hline USA & 2000 & $\mathrm{~F}$ & & 81 \\
\hline
\end{tabular}

A one percent reduction in the force of mortality at all ages would produce much less increase in life expectancy today than it would fifty years or a century ago. This decline is, in large measure, a price of the progress that has been made in reducing deaths in infancy--the age at which the most years of life expectancy are lost. Another result of this progress is a shift in the ages where further progress against mortality would be most effective in increasing life expectancy. Before 1900, most of the potential for saving life years was concentrated in the first five years of childhood; today, in developed countries, most of the potential is in old age. Table 3 shows the decline in $H$ and the shift in the profile of $\eta$ by presenting data based on Swedish life tables from 1800 to 1980. Keyfitz [3] shows the decline in $H$ for U.S. males and females from 1920 to 1960.

As Pollard [1] demonstrates, more rapid progress against mortality may be occurring at all ages in one population compared with another, but nonetheless life expectancy may be increasing less rapidly. This seeming paradox is less puzzling when viewed through the lens of $\eta$. Let $\rho_{i}(a)$ be the rate at which the force of mortality is being reduced at age $a$ in population $i$. Suppose

$$
\rho_{1}(a)>\rho_{2}(a) \text {, all } a \text {, }
$$


but that

$$
\eta_{1}(a) \rho_{1}(\alpha)<\eta_{2}(\alpha) \rho_{2}(\alpha) \text {, all } a \text {. }
$$

Then it follows from (16) that life expectancy will be increasing less rapidly in the first population than in the second.

Table 3. The potential for saving life years $(H)$, the proportion of this potential below age 5 and above age 65, and life expectancy at birth for selected Swedish populations.

\begin{tabular}{lcccc}
\hline Period & $H$ & $\int_{0}^{5} \eta(x) d x / H$ & $\int_{65}^{\omega} \eta(x) d x / H$ & ${ }^{0}$ \\
& \multicolumn{5}{c}{ Males } \\
& \multicolumn{4}{c}{} \\
1800 & .772 & .584 & .050 & 33.7 \\
1820 & .722 & .534 & .056 & 35.4 \\
1840 & .636 & .490 & .065 & 35.4 \\
1860 & .587 & .482 & .096 & 43.2 \\
1880 & .545 & .458 & .116 & 46.2 \\
1900 & .432 & .398 & .130 & 52.0 \\
1920 & .346 & .305 & .172 & 57.5 \\
1940 & .238 & .233 & .273 & 65.0 \\
1960 & .167 & .130 & .428 & 71.2 \\
1980 & .157 & .060 & .476 & 72.7
\end{tabular}

Females

\begin{tabular}{lllll}
1800 & .712 & .567 & .066 & 36.9 \\
1820 & .663 & .507 & .075 & 39.0 \\
1840 & .573 & .471 & .092 & 43.1 \\
1860 & .538 & .461 & .119 & 46.7 \\
1880 & .509 & .431 & .136 & 49.2 \\
1900 & .403 & .366 & .152 & 54.6 \\
1920 & .318 & .272 & .199 & 60.1 \\
1940 & .211 & .198 & .324 & 67.7 \\
1960 & .142 & .116 & .530 & 74.9 \\
1980 & .126 & .058 & .613 & 79.0 \\
\hline
\end{tabular}

NOTE: The life tables used before 1900 included no estimate of the force of mortality after age 85 . For these tables the value of $\int_{B S}^{\infty} \eta(x) d x$ was assumed to equal $\int_{\text {Bo }}^{85} \eta(x) d x$. This approximation is based on the life tables for which mortality rates are available after age 85. 
Clearly the condition in (28) can be relaxed; essentially what is required is that $\eta_{1}$ be sufficiently smaller than $\eta_{2}$ at enough ages. As indicated in Table 3 and as discussed by Keyfitz [3], the value of $H$, the integral of the $\eta$ 's, tends to fall as life expectancy increases; as $H$ falls, the value of $\eta$ at most ages also must fall. Thus as life expectancy increases progress in reducing age-specific mortality translates into less and less progress in further increasing life expectancy. A population with a higher life expectancy than a second population can be making greater progress against mortality at all ages but nonetheless be making less progress in increasing life expectancy.

\section{RATES OF PROGRESS AGAINST MORTALITY}

The potential for saving life years is measured by $\eta$; progress against mortality is given by $p$. As indicated by (16), progress in increasing life expectancy, as measured by $\pi$, depends on the product of $\eta$ and $\rho$. Thus, even if the potential for saving life years is greatest in old age, if little progress is being made in reducing mortality at older ages then this potential will not translate into life expectancy gains.

Table 4 presents data on $\eta$ and $\rho$ for Swedish females in 1982. Progress in reducing mortality is highest in infancy and childhood; afterwards, the annual rate of progress hovers between one and two percent or so at most ages. Because of the rapid rate of progress in the childhood years, almost a sixth of the life expectancy gains occur before age 20 even though less than a tenth of the potential lies in these years. By age 55, however, potential and actual progress are in rough balance: seventy percent of the potential for saving life years occurs after age 55 and seventy percent of the actual improvement in life expectancy can be attributed to progress made in reducing mortality after age 55.

It may seem a bit surprising that progress in reducing mortality rates hovers around roughly the same level at all ages after childhood and that significant improvements are being made at older ages. Table 5 presents data on trends in mortality rates since 1780 for Swedish females and males and since 1920 for U.S. females and males. In most cases, progress in reducing mortality after age 85 is comparable to the progress made between ages 5 and 65 . Except for Swedish males, progress since 1950 and especially since 1970 against mortality in old age has been substantial. (For a discussion of recent U.S. mortality trends, see [9].) 
Table 4. Average values of $\eta$ and $\rho$ in various age categories and the cumulative percentage of $\eta$ and of the product of $\eta \rho$ up through these age categories, for Swedish females in 1982.

\begin{tabular}{lccccc}
\hline & \multicolumn{3}{c}{$\int_{0}^{a} \eta(x) d x$} & & $\int_{0}^{a} \eta(x) \rho(x) d x$ \\
\cline { 3 - 4 } Age Category & & & \\
\cline { 3 - 5 } (through age $a)$ & $\bar{\eta}$ & $\int_{0}^{\omega} \eta(x) d x$ & $\bar{\rho}$ & $\int_{0}^{\omega} \eta(x) \rho(x) d x$ \\
\hline $0-5$ & & & & \\
$5-10$ & .00149 & $5.9 \%$ & $3.0 \%$ & $9.3 \%$ \\
$10-15$ & .00014 & 6.4 & 7.3 & 11.4 \\
$15-20$ & .00012 & 6.9 & 3.5 & 12.3 \\
$20-25$ & .00021 & 7.7 & 4.4 & 14.3 \\
$25-30$ & .00024 & 8.7 & 2.8 & 15.6 \\
$30-35$ & .00028 & 9.8 & 1.6 & 16.6 \\
$35-40$ & .00034 & 11.1 & 1.1 & 17.3 \\
$40-45$ & .00049 & 13.1 & 1.7 & 19.1 \\
$45-50$ & .00063 & 15.5 & 2.0 & 21.7 \\
$50-55$ & .00090 & 19.1 & 1.4 & 24.4 \\
$55-60$ & .00119 & 23.8 & 1.5 & 28.2 \\
$60-65$ & .00156 & 30.0 & 0.7 & 30.5 \\
$65-70$ & .00189 & 37.4 & 1.5 & 36.4 \\
$70-75$ & .00243 & 46.9 & 1.5 & 44.0 \\
$75-80$ & .00297 & 58.6 & 1.8 & 55.2 \\
$80-85$ & .00340 & 72.0 & 2.0 & 69.5 \\
$85-90$ & .00334 & 85.2 & 1.7 & 81.3 \\
$90-95$ & .00242 & 94.7 & 2.0 & 91.5 \\
$95-100$ & .00108 & 98.9 & 2.9 & 98.1 \\
\hline & .00027 & 100. & 3.4 & 100. \\
\hline
\end{tabular}

NOTE: The rate of progress in reducing mortality, $\bar{\rho}_{1}$ is the average rate from 1970 to 1982 . The formulas used to calculate $\bar{\eta}$ and $\bar{\rho}$ are:

$$
\bar{\eta}=\frac{n d_{x}}{n} \cdot \frac{\dot{e}_{x}+\dot{e}_{x+n}}{2} / \dot{e}_{0}, \quad(\text { where } x+n=a),
$$

and

$$
\bar{\rho}=\left(\ln \left(-\ln \left(1-{ }_{n} q_{n}^{\prime}\right)\right)-\ln \left(-\ln \left(1-{ }_{n} q_{x}\right)\right)\right) / t,
$$

where $q^{\prime}$ is from the earlier life table and $t$ is the number of years that have elapsed.

Suppose progress against mortality continues. Will. $H$ decline much further? Will life expectancy level off as it becomes more and more difficult to increase life expectancy by decreasing mortality rates? Some insight into these questions can be gained by a simple model. Assume that the force of mortality can be described by a Gompertz curve, as given in (24). This is not an unreasonable assumption for our purposes here, given the low level of mortality in infancy and childhood in developed countries. Furthermore, because 
Table 5. The average annual rate of progress $\bar{\rho}$ in reducing the force of mortality for Swedish females and males from 1780 to 1982 and for U.S. females and males for 1920 to 1979 for various age categories.

\begin{tabular}{lclllll}
\hline & & \multicolumn{5}{c}{ Age Category } \\
\cline { 3 - 7 } Population & Period & $0-5$ & $5-25$ & $25-45$ & $45-65$ & $65-85$ \\
\hline Swedish F & $1780-1870$ & $0.4 \%$ & $0.4 \%$ & $0.3 \%$ & $0.1 \%$ & $0.1 \%$ \\
& $1870-1910$ & 2.1 & 0.8 & 0.7 & 1.1 & 0.8 \\
& $1910-1950$ & 3.9 & 4.9 & 3.5 & 1.1 & 0.2 \\
& $1950-1970$ & 3.4 & 2.3 & 2.1 & 1.8 & 1.6 \\
Swedish M & $1970-1982$ & 3.0 & 4.3 & 1.7 & 1.3 & 1.8 \\
& $1780-1870$ & 0.4 & 0.5 & 0.2 & 0.0 & -0.1 \\
& $1870-1910$ & 2.0 & 1.0 & 1.0 & 1.3 & 0.9 \\
& $1910-1950$ & 3.6 & 3.6 & 2.9 & 1.0 & 0.2 \\
& $1950-1970$ & 3.2 & 1.7 & 0.5 & 0.3 & 0.4 \\
U.S. F & $1970-1982$ & 4.7 & 3.9 & 0.6 & 0.3 & 0.1 \\
& $1920-1950$ & 3.9 & 5.5 & 4.0 & 1.8 & 1.2 \\
& $1950-1970$ & 2.5 & 1.5 & 1.4 & 1.3 & 1.2 \\
U.S. M & $1970-1979$ & 4.8 & 2.3 & 3.6 & 2.1 & 2.7 \\
& $1920-1950$ & 3.7 & 1.3 & 3.5 & 0.3 & 0.5 \\
& $1950-1970$ & 2.6 & -0.1 & 0.3 & 0.4 & 0.2 \\
& $1970-1979$ & 5.0 & 1.7 & 2.3 & 2.4 & 1.9 \\
\hline
\end{tabular}

NOTE: The values of $\bar{\rho}$ were calculated using the formula given in Table 4.

Table 6. Values of $\stackrel{\circ}{e}_{0}$ and $H$ over time, when the force of mortality follows a Gompertz curve and is being reduced one percent per year before age 85 , for various assumptions about the rate of aging, $\beta$, and the rate of progress against mortality after age 85 .

\begin{tabular}{|c|c|c|c|c|c|c|c|}
\hline \multirow[b]{2}{*}{$\beta$} & \multirow[b]{2}{*}{ Year } & \multicolumn{2}{|c|}{$\rho=0$ after 85} & \multicolumn{2}{|c|}{$p=0.5 \%$ after 85} & \multicolumn{2}{|c|}{$\rho=1 \%$ after 85} \\
\hline & & $\dot{\theta}_{0}$ & $H$ & $\begin{array}{l}0 \\
e_{0} \\
\end{array}$ & $H$ & $\begin{array}{l}0_{0} \\
e_{0}\end{array}$ & $H$ \\
\hline \multirow[t]{4}{*}{0.08} & 0 & 75.0 & .165 & 75.0 & .165 & 67.5 & .165 \\
\hline & 100 & 83.0 & .111 & 85.4 & .126 & 87.4 & .142 \\
\hline & 200 & 88.3 & .075 & 93.1 & .102 & 99.9 & .125 \\
\hline & 300 & 90.2 & .059 & 99.1 & .093 & 112.4 & .110 \\
\hline \multirow[t]{4}{*}{0.12} & 0 & 75.0 & .111 & 75.0 & .111 & 75.0 & .111 \\
\hline & 100 & 81.7 & .079 & 82.4 & .089 & 83.3 & .100 \\
\hline & 200 & 85.5 & .051 & 88.0 & .070 & 91.7 & .091 \\
\hline & 300 & 87.2 & .037 & 92.0 & .063 & 100.0 & .083 \\
\hline
\end{tabular}




$$
\dot{e}_{0}=\int_{0}^{\omega} x \mu(x) p(x) d x
$$

it is clear that life expectancy is largely determined by mortality at the ages between 35 and 90 or 95 for which a Gompertz curve generally provides an adequate fit to the force of mortality.

Table 6 projects life expectancy over a period of 300 years under various assumptions. The value of $\beta$ in the Gompertz curve is taken to be either .08 or .12--values roughly bracketing the values observed in developed countries. Progress in reducing mortality before age 85 is assumed to be one percent per year; after age 85, progress is either one percent per year, half of percent per year, or zero.

Table 6 shows that $H$ does continue to fall as life expectancy increases. When there is no progress against mortality after age $85, H$ falls to especially low levels and life expectancy does show some signs of leveling off--at a level well above 85 . When mortality at advanced ages is reduced by one percent per year, life expectancy increases to a century or more. And even when the rate of progress is only half a percent per year, life expectancy rises into the 90's. A rate of progress of one percent a year does not seem unreasonable in light of the statistics presented in Table 5 and given the ignorance and uncertainty enveloping our understanding of aging processes [10,11]. Indeed, a rate of two percent per year might be plausible, in which case the 300 years in Table 6 would be compressed into a century and a half.

Progress in increasing life expectancy is greater when $\beta$, the rate of aging, is lower. This suggests that reductions in $\beta$ might be far more effective than reductions in $\alpha$. If $\beta$ is cut from .12 to .08 , then death rates at all ages must be multiplied by a factor of nearly 14 before life expectancy returns to its original level.

The data in Table 6 indicate that when progress against mortality is uniform at all ages, then the gain in life expectancy each century is roughly the same--about 12.5 years when $\beta=.08$ and 8.4 years when $\beta=.12$. Thus, although $H$, which measures the relative or proportional rate of increase in life expectancy, is decreasing, the absolute rate of increase, given by ${ }^{0} e_{0} / d t$, seems to remain more or less constant. The truth of this is readily demonstrated. If mortality rates follow a Gompertz curve and if steady progress at rate $\rho$ is being made in reducing mortality rates, then 


$$
\begin{aligned}
& \dot{e}_{0}(t)=\int_{0}^{\omega} p(a, t) d a \\
& =\int_{0}^{\omega} e^{-\frac{a}{\beta} e^{-\rho t}\left(\varepsilon^{\beta x}-1\right)} d x .
\end{aligned}
$$

Elementary methods of differential calculus yield the result

$$
\frac{d e_{0}(t)}{d t}=\frac{\rho}{\beta}\left[\int_{0}^{\omega} p(x, t) \mu(x, t) d x-\alpha e^{-p t} \int_{0}^{\omega} p(x, t) d x\right]
$$

The first integral is simply the integral of the density of death and hence equals one; the second integral equals life expectancy at birth. Letting

$$
\alpha^{\prime}=\alpha e^{-\rho t}
$$

the result simplifies to

$$
\frac{\stackrel{0}{d e_{0}}(t)}{d t}=\frac{e}{\beta}\left[1-\alpha^{\prime} e_{0}\right]
$$

If $\alpha^{\prime}$ is small, which it will be for a population with a long life expectancy (because for such a population either $\alpha$ will be small or $\rho t$ will be large), then the change in life expectancy over time will be roughly constant:

$$
\frac{d e_{0}(t)}{d t} \approx \frac{\rho}{\beta}
$$

\section{THE IMPACT OF HETEROGENEATY}

The assumption is questionable that those who die at some age would, if saved, have the same life expectancy as those who live. For instance, as discussed in [12], the victim of a serious heart attack or motor vehicle accident might, if death were averted, be prone to another heart attack or motor vehicle accident. More generally, individuals of the same age may differ from each other in their "frailty" or relative risk of death $[13,14,15]$. Let the life expectancy of those who are saved at age $a$ (i.e., the average number of years, under current mortality conditions, that these individuals would live if death could be averted) be denoted by $e^{+}(a)$. In a homogeneous population, this life expectancy would 
equal $\stackrel{e}{e}(a)$; in a heterogeneous population it will probably be lower, although it could, conceivably, be higher. Then, (15) becomes

$$
\eta(a)=\mu(a) p(a) e^{+}(a) / \dot{e}_{0}
$$

As before,

$$
H=\int_{0}^{\infty} \eta(\alpha) d \alpha
$$

As a simple example, suppose $e^{+}$were only half $\stackrel{0}{e}$ at all ages. The values of $\eta$ and the value of $H$ would be half as great as the assumption of homogeneity would indicate. The profile of the $\eta$ 's would be the same--and hence the age at which there was the greatest potential for saving life years would not change-but the impact of a one percent reduction in death rates on life expectancy would be cut in half.

\section{THE LAFE EXPECTANCY OF THE DFAD}

More elaborately, following [13], let $z$ be a measure of frailty or relative risk such that an individual at some particular age with frailty $z$ is subject to a force of mortality that is $z$ times greater than the force of mortality of a "standard" individual of the same age who has a frailty value of one. Then $e^{+}$can be calculated if a distribution is specified for $z$.

As noted by Beard [16] and others, the Gamma distribution is a plausible, tractable, and flexible probability distribution to use when studying heterogeneous populations. Vaupel et al. [13] prove that if $z$ is Gamma distributed at age a with shape parameter $k$ and scale parameter $\lambda_{1}$ then the frailty of those who die at age $a$ follows a Gamma distribution with the same scale parameter $\lambda$ and with shape parameter $k+1$. Consider the two cohorts of those who would ordinarily survive at age $a$ and those who would have died but are saved-and hence die later. If individual frailty does not change after age $a$, if $\bar{z}(x)$ and $\bar{z}^{+}(x)$ are the mean frailties of the surviving members of the two cohorts at age $x>a$, and if $\mu$ represents the force of mortality for the standard individual, then it can be shown that

$$
\bar{z}(x)=\frac{k}{\lambda+\int_{a}^{x} \mu(t) d t}
$$




$$
\bar{z}^{+}(x)=\frac{k+1}{\lambda+\int_{a}^{x} \mu(t) d t} .
$$

Because, as shown in [13], the force of mortality among surviving individuals is given by

$$
\bar{\mu}(x)=\mu(x) \bar{z}(x),
$$

the force of mortality among the survivors of the saved cohort will be

$$
\bar{\mu}^{+}(x)=\bar{\mu}(x) \frac{k+1}{k}
$$

If individual frailty is constant at all ages after birth, then

$$
\frac{k+1}{k}=1+\sigma^{2}
$$

where $\sigma^{2}$ is the variance in frailty at birth. Let $s(a, x)$ represent the proportion of those alive at age $a$ who are surviving at age $x>a$ :

$$
s(a, x)=p(x) / p(a)=e^{-\int_{a}^{x} \bar{\mu}(t) d t} .
$$

Clearly,

$$
s^{+}(a, x)=s(a, x)^{1+\sigma^{8}}
$$

Consequently, the life expectancy of those whose death is averted at age $a$ is given by:

$$
e^{+}(a)=\int_{a}^{\infty} p(x)^{1+\sigma^{2}} d x / p(a)^{1+\sigma^{2}}
$$

Indeed, (44) has a broader interpretation because of the remarkable result in (40): the force of mortality at age $x$ is the same for all the cohorts of survivors of those saved at any age before $x$. Thus, (44) gives the life expectancy at age a of the survivors of those whose death was averted at any age before $a$.*

\footnotetext{
The formulas for $\bar{\mu}^{+}$and $e^{+}$in (40) and (44) readily generalize to cohorts for whom death is averted more than once, e.g., those who would die at some age but are saved and then would die at some later age and are saved again. For those who are saved $m$ times, substitute $m+\sigma^{2}$ for $1+\sigma^{2}$.
} 
Estimates of $\sigma^{2}$ are available from three studies. The eight estimates in [17] range from 0.25 to 1.67 ; the median is 0.37 . The eight estimates in [18] range from .12 to .54; the median is .22. Finally, the parameters estimated in [19] imply a value of $\sigma^{2}$ of .22 for the model the fit the data best and a value of .03 for a model that fit less well. All these estimates are based on data for elderly populations and on the assumption that individual frailty does not change with age and follows a Gamma distribution. Although the estimates are subject to question, it seems plausible that an appropriate value of $\sigma^{2}$ may be of the order of magnitude of 0.1 to 1.0 and that a best guess might be 0.25 .

Table 7 presents life expectancies for those who die at various ages (if they were saved) and the corresponding values of $\eta$. for five values of $\sigma^{2}$. When $\sigma^{2}$ is zero, the population is homogeneous and the life expectancy of those who die is the same as the life expectancy of those who live. Note that the effect of heterogeneity is to reduce life expectancy by a greater absolute amount at younger ages but by a greater proportional amount at older ages. If, for example, $\sigma^{2}$ is one, then at age zero the life expectancy of those who die is more than 7 years less, but still about $90 \%$ of, the life expectancy of those who survive. At age 90 . the loss is only 1.5 years, but this is nearly half of a ninety-year-old's life expectancy.

It is the proportional losses that affect $\eta$ and $H$; consequently, the greater the heterogeneity, the lower the value of $H$ and the more the potential for saving lives lies at younger ages. As the table shows, however, even if $\sigma^{2}$ were as high as one, $H$ would fall by less than a third, from .127 to .091 , and the potential for saving life years by averting deaths above age 65 would only fall from 60 percent to 54 percent of the total potential.

A more general model of the life expectancy of those saved from death can be constructed as follows. Let $\mu_{\mathfrak{a}}^{+}(x)$ represent the force of mortality at age $x$ of those who would have died at age $a<x$, perhaps from some specified cause, but were saved. Let the risk ratio be given by

$$
\gamma_{\mathbf{a}}(x)=\mu_{a}^{+}(x) / \mu(x)
$$

where $\mu(x)$ is simply the force of mortality at age $x$ (i.e., among those who would not have died). Then it follows from (42) that

$$
s^{+}(a, x)=e^{-\int_{a}^{x} \gamma_{a}(t) \mu(t) d t}
$$


Table 7. Life expectancies of those saved from death and resulting profles of $\eta$ for various values of $\sigma^{2}$, the variance in frailty at birth, for Swedish females in 1978.

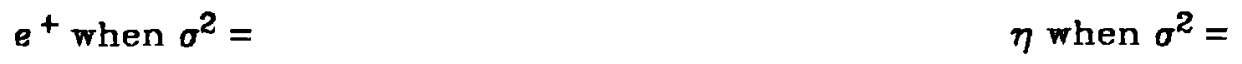

\begin{tabular}{|c|c|c|c|c|c|c|c|c|c|c|c|c|}
\hline Age & 0 & .1 & .25 & .5 & 1 & 4 & 0 & .1 & .25 & .5 & 1 & 4 \\
\hline 0 & 78.5 & 77.5 & 78.2 & 74.3 & 71.2 & 60.3 & .00667 & .00859 & .00648 & .00832 & .00605 & .00512 \\
\hline 10 & 69.2 & 68.3 & 67.1 & 65.3 & 62.5 & 53.0 & .00012 & .00012 & .00012 & .00012 & .00011 & .00009 \\
\hline 20 & 59.4 & 58.5 & 57.3 & 55.6 & 52.8 & 43.7 & .00034 & .00033 & .00033 & .00032 & .00030 & .00025 \\
\hline 30 & 49.6 & 48.8 & 47.6 & 45.9 & 43.3 & 34.6 & .00033 & .00033 & .00032 & .00031 & .00029 & .00023 \\
\hline 40 & 40.0 & 39.2 & 38.0 & 36.4 & 33.9 & 25.8 & .00066 & .00065 & .00063 & .00060 & .00056 & .00043 \\
\hline 50 & 30.7 & 29.9 & 28.8 & 27.3 & 25.0 & 18.0 & .00112 & .00110 & .00106 & .00100 & .00092 & .00066 \\
\hline 60 & 21.8 & 21.1 & 20.2 & 18.9 & 16.9 & 11.2 & .00175 & .00170 & .00162 & .00152 & .00135 & .00090 \\
\hline 70 & 13.8 & 13.2 & 12.4 & 11.3 & 9.8 & 5.7 & .00279 & .00267 & .00251 & .00230 & .00198 & .00116 \\
\hline 80 & 7.3 & 6.9 & 6.3 & 5.6 & 4.6 & 2.2 & .00348 & .00328 & .00301 & .00266 & .00217 & .00104 \\
\hline 90 & 3.2 & 3.0 & 2.7 & 2.3 & 1.7 & 0.6 & .00138 & .00127 & .00114 & .00097 & .00073 & .00026 \\
\hline$H$ & & & & & & & .127 & .121 & .115 & .105 & .091 & .055 \\
\hline $\int_{65} \eta(x) d x / H$ & & & & & & & $60 \%$ & $60 \%$ & $58 \%$ & $56 \%$ & $54 \%$ & $43 \%$ \\
\hline
\end{tabular}


Thus, letting $e_{a}^{+}(x)$ denote the life expectancy at age $x$ of those who were saved from death at age $\alpha$,

$$
e_{a}^{+}(x)=\int_{a}^{\infty} e^{-\int_{a}^{x} \gamma_{a}(t) \mu(t) d t}
$$

Various special cases of this general result may be of interest. For instance, $\gamma_{a}(t)$ could be constant for all $t$, could gradually decline toward one, or could be constant for a decade, say, and then fall to one. If

$$
\gamma_{a}(t)=\gamma_{a} \text {, all } t
$$

then (47) implies

$$
e_{a}^{+}(\alpha)=\int_{a}^{\omega} p(x)^{\gamma_{a}} d x / p(a)^{\gamma_{a}}
$$

The similarity of this formula to (44) means that the values in Table 7 for $\sigma^{2}$ equal to 0 to 4 can be interpreted as pertaining to $\gamma_{a}$ equal to 1 to 5 . For example, consider a group of 50-year-olds who would have died from a heart attack but were saved. Suppose this group would face a force of mortality, for the rest of their lives, some five times greater than the normal force of mortality. Then their remaining life expectancy would be 18.0 years, rather than the normal 30.7 years. *

\section{POLICY IMPLICATIONS AND INSINUATIONS}

As discussed by Vaupel [20], nearly all statistics presented in policyrelevant studies are really vectors: they not only summarize a body of data, but they also imply a policy thrust. Implicational honesty requires some discussion of lurking insinuations that may appear to be simple facts. If mortality rates were reduced by one percent, over 60 percent of the life years gained would be gained by averting deaths above age 65 . Does this imply that the life-saving efforts should be directed toward the elderly population? Not necessarily, for several reasons. First, the 60 percent figure is based on the 1982 life table for Swedish females. For males and for other countries the figure is generally the same way that [\$] and [1] generalize their formulas. 
lower--for Swedish males in 1982 it is under 50 percent. Heterogeneity, as discussed above, would reduce this somewhat further.

Second, the figure is based on a life table-i.e., on a hypothetical, stationary population--rather than on the actual distribution of a population by age. In most populations there are more young people than implied by the life table. Consequently, the goal of increasing life expectancy is not completely congruent with the goal of saving as many life years as possible given the current population distribution. For instance, for the total U.S. life table for 1979 , about 50 percent of the increase in life expectancy produced by a one percent reduction in mortality rates can be attributed to the reduction in mortality rates above age 65 . However, only about 36 percent of the gain in life years produced by a one percent reduction in the actual number of deaths at all ages would be due to averting deaths above age 65 .

Third, the quality of life at advanced ages may tend, on average, to be lower than at younger ages. If the goal is to save as many quality-adjusted life years as possible [12], then efforts to avert deaths at younger ages will appear more favorable. Other goals that might be proposed--e.g., maximize life years saved before the Biblical allotment of three score and ten, maximize economic production, minimize deaths of parents with young children, or minimize inequalities in lifespans--also favor efforts to reduce early deaths. Vaupel [21, 22] examines several criteria and concludes that most of the losses due to death are due to deaths before age 65 .

Fourth, it may be easier to avert deaths before age 65 than afterwards. As the data presented on the rate of progress against mortality show, progress against early death has generally tended to be somewhat more rapid than progress against death after age 65.

Offsetting these considerations are many others. As Vaupel and Yashin [14] suggest, the true rate of progress being made in reducing mortality rates at advanced ages may be masked by the effects of heterogeneity. The quality of life of many of those who die before age 65 may be relatively low, even if the quality of life at younger ages does tend to be higher than that after, say, age 85. Furthermore, those who die early may tend to be the kind of people who, if saved, would have relatively short life expectancies. Finally, there are several appealing objectives that favor life saving at older ages. It is desirable to avert death per se, regardless of life expectancy, and most deaths occur in old age. It is desirable to have a society that is diverse in its age composition--and in its memories and 
experiences. Persons born in the 19th century, who experienced the world with Kaiser Franz Joseph and without radio, are not only relatively rare but also constitute, in a sense, an endangered species that will be extinct in a few years.

Suppose it were possible to save the lives of ten 80-year-olds, giving them, on average, seven additional years of life. And suppose the alternative was to save the lives of two 40-year-olds, giving each of them an expected additional lifespan of 35 years. Either way, 70 years of life expectancy are gained. Which alternative would be preferable? Recommendations concerning the focus of policies to save lives depend not only on statistical analyses but also on answers to such difficult value questions.

Beyond this, policy decisions are usually made concerning specific lifesaving alternatives. Should an extra million dollars be devoted to research on influenza? Should passive restraint systems for automobiles be required? These decisions depend not only on broad value judgments but also on the details of the specific proposal. How effective is it likely to be? How much will it cost? How many voters will like it?

Nonetheless, the methods and findings of this paper may be of some relevance to policy discussions. In particular, there is considerable potential for saving life years and increasing life expectancy by reducing mortality in old age, more potential than generally realized. Furthermore, because considerable progress is being made in reducing mortality among the elderly, this potential is being realized. The result is a shift in the age composition of the population: progress in reducing mortality rates is adding relatively few life years among the working-age population compared with the extra life years added after age 65 .

\section{References}

1. J.H. Pollard, "The Expectation of Life and Its Relationship to Mortality," Journal of the Institute of Actuaries 109(2), pp.225-240 (1982).

2. United Nations, Levels and Trends of Mortality Since 1950, United Nations, New York (1982).

3. N. Keyfitz, Applied Mathematical Demography, Wiley, New York (1977). 
4. L. Demetrius . "Demographic Parameters and Natural Selection," Proceedings of the National Academy of Sciences 71(12), pp.4645-4647 (1974).

5. L. Demetrius, “Adaptive Value, Entropy, and Survivorship Curves," Nature 275(September 21), pp.213-214 (1978).

6. N. Keyfitz, "Choice of Function for Mortality Analysis: Effective Forecasting Depends on a Minimum Parameter Representation," Theoretical Population Biology 21(3), pp.329-352 (1981).

7. N. Keyfitz and W. Flieger, World Population: An Analysis of Vital Data, University of Chicago Press, Chicago (1968).

8. S.H. Preston, N. Keyfitz, and R. Schoen, Causes of Death: Life Tables for National Populations, Seminar Press, New York (1972).

9. E.M. Crimmins, "The Changing Pattern of American Mortality Decline, 1940-1977, and Its Implications for the Future," Population and Development Review 7(2), pp.229-254 (1981).

10. K.G. Manton, "Changing Concepts of Morbidity and Mortality in the Elderly Population," Milbank Memorial Fund Quarterly/Health and Society 60. pp.183-244 (1982).

11. J.M. Owen and J.W. Vaupel, "Anna's Life Expectancy", WP-85-11, International Institute for Applied Systems Analysis, Laxenburg, Austria (1985). Forthcoming in American Demographics.

12. R. Zeckhauser and D. Shepard, "Where Now for Saving Lives?," Law and Contemporary Problems 40(4), pp.5-45 (1976).

13. J.W. Vaupel, K.G. Manton, and E. Stallard, "The Impact of Heterogeneity in Individual Frailty on the Dynamics of Mortality," Demography 16, pp.439454 (1979).

14. J.W. Vaupel and A.I. Yashin. "The Deviant Dynamics of Death in Heterogeneous Populations", RR-83-1, International Institute for Applied Systems Analysis (1983). An abridged version is in Nancy Tuma (ed.) Sociological Methodology 1985, Jossey-Bass, San Francisco.

15. J.W. Vaupel and A.l. Yashin, "Heterogeneity's Ruses: Some Surprising Effects of Selection on Population Dynamics," Forthcoming in The American Statistican, August 1985. 
16. R.E. Beard, "A Theory of Mortality Based on Actuarial, Biological and Medical Considerations," (1963). Proceedings of International Population Conference, New York, 1961, volume 1, pp.611-625

17. K.G. Manton, E. Stallard, and J.W. Vaupel, "Methods for Comparing the Mortality Experience of Heterogeneous Populations," Demography 18(3), pp.389-410 (1981).

18. K.G. Manton, E. Stallard, and J.W. Vaupel, "Alternative Estimates of the Heterogeneity of Mortality Risks Among the Aged," Submitted to the Journal of the American Statistical Association (1984).

19. S. Horiuchi and A.J. Coale, "Age Patterns of Mortality for Older Women: An Analysis Using the Age-Specific Rate of Mortality Change with Age," (1983). Presented at Population Association of America meeting, Pittsburgh, Pennsylvania, April 14-16, 1983

20. J.W. Vaupel, "Statistical Insinuation," Journal of Policy Analysis and Management 1(2), pp.261-263 (1982).

21. J.W. Vaupel, "Early Death: An American Tragedy," Law and Contemporary Problems 40(4). pp.73-121 (1976).

22. J.W. Vaupel, "The Prospects for Saving Lives: A Policy Analysis". Working Paper \#778, Institute for Policy Sciences and Public Affairs, Duke University, Durham, N.C. (1978). Reprinted in Comparative Risk Analysis, Committee on Science and Technology, U.S. House of Representatives, 1980. 